Piotr Stalmaszczyk

Uniwersytet Łódzki

Instytut Anglistyki

\title{
DEMINUTYWA W JĘZYKU IRLANDZKIM ORAZ W IRLANDZKIEJ ODMIANIE JĘZYKA ANGIELSKIEGO
}

\section{UWAGI WSTEPPE}

Na skutek wydarzeń historycznych, sytuacji politycznej oraz geopolitycznej, we współczesnej Irlandii podstawowym językiem jest angielski, natomiast język irlandzki, o nieporównywalnie dłuższej historii, jest, mimo konstytucyjnej ochrony, językiem mniejszościowym. Wielowiekowe kontakty pomiędzy obydwoma językami doprowadziły do, z jednej strony, poważnego osłabienia języka irlandzkiego, z drugiej, do powstania regionalnej odmiany języka angielskiego, obfitującej w regionalizmy pochodzenia substratowego. Terminem ,irlandzka odmiana języka angielskiego" określam tu zbiorowo dialekty języka angielskiego występujące historycznie i współcześnie w Irlandii, niezależnie od historii, warunków ich powstawania i regionalnego zróżnicowania. Odmiana ta rozwijała się pod znacznym wpływem języka irlandzkiego, co widoczne jest w słownictwie i frazeologii, fonetyce oraz składni ${ }^{1}$.

\footnotetext{
Zob. szczegółowe klasyczne już opracowania: Bliss, 1972, 1979; Hogan, 1927; Joyce, 1979, a z nowszych prac przede wszystkim Hickey, 2007 i Corrigan, 2010. W niektórych opracowaniach przyjmuje się nazwę Hiberno-English 'hiberno-angielski'. Według Alana Blissa [1972, s. 63] odmiana ta powstała na bazie siedemnastowiecznego języka angielskiego, przejętego i zmodyfikowanego przez użytkowników języka irlandzkiego, natomiast Terence Dolan [2004, s. XXI] określa hiberno-angielski jako codzienny język Irlandii, mieszankę irlandzkiego i angielskiego. W anglojęzycznej literaturze pojawiają się też terminy Irish English (jako najbardziej neutralny), Anglo-Irish (zdecydowanie najbardziej nacechowany); zob. omówienie w Hickey, 2007.
} 
Wśród elementów irlandzkich, występujących w słownictwie tej odmiany, można wyróżnić różne typy zapożyczeń, formy hybrydalne, kalki semantyczne, thumaczone zwroty oraz wyrażenia wykrzyknikowe i tzw. „,czułe słówka”. Zapożyczenia irlandzkie w znacznej większości mają charakter lokalny i nie przedostały się do ogólnego języka angielskiego, natomiast nadają charakterystycznego kolorytu irlandzkiej odmianie języka angielskiego i są często stosowane w tekstach literackich, zwłaszcza stylizacjach.

Celem niniejszego artykułu jest krótkie przedstawienie deminutywów w języku irlandzkim oraz omówienie i wstępna klasyfikacja deminutywów występujących w irlandzkiej odmianie języka angielskiego.

Oprócz typowych pożyczek leksykalnych (zwłaszcza dotyczących elementów kulturowych), warto zwrócić uwagę na występowanie form hybrydalnych z podstawą angielską i przyrostkiem irlandzkim, zwłaszcza irl. -ín / ang.-irl. -een (omówionych dokładniej poniżej), a także na kalki semantyczne - dosłowny przekład poszczególnych elementów irlandzkich na język angielski - np. wyrażenia z przymiotnikami $d u b h$ 'czarny' i dearg 'czerwony', które w języku irlandzkim moga pełnić rolę wzmacniającą i metaforyczną.

Podane poniżej przykłady pochodzą przede wszystkim z opracowań leksykograficznych, słowników i leksykonów, odnotowanych w bibliografii do niniejszego artykułu:

- zapożyczenia:

banshee 'zjawa' ( $<$ irl. bean 'kobieta' + sidhe 'wzgórze wróżek'); boreen 'ścieżka, dróżka' (< irl. bóthairín, id.); brogue 'but' (< irl. bróg, id.); keen 'lament; tren' ( $<$ irl. caoin 'lament'); colleen 'dziewczę' ( $<$ irl. cailín, id.); galore 'dostatek, mnóstwo' ( $<$ irl. go + leór, wyrażenie występuje w postpozycji, np. there was whiskey galore 'było mnóstwo whisky'); sally 'wierzba' ( $<$ irl. saileach 'wierzba'); slan 'na zdrowie' ( $<$ irl. slán 'zdrowie'); turas 'pielgrzymka, nawiedzenie' (irl. turas, id.);

- hybrydy:

boyeen 'chłopaczek'; girleen 'dziewczę'; maneen 'człowieczek'; gortweed 'polny chwast' (irl. gort 'pole' + ang. weed 'chwast'); ban-daisy 'jastrun' (irl. bán 'biały' + ang. daisy 'stokrotka')';

Dla potrzeb niniejszego artykułu posługuję się jedynie terminem 'irlandzka odmiana języka angielskiego' i skrótem irl.-ang., artykuł nawiązuje do wcześniejszych opracowań: Stalmaszczyk, 2007, 2009, tamże dodatkowa bibliografia oraz przykłady ze źródeł literackich.

2 Dwa ostatnie słowa odnotowane są w słownikach ulsterskiej odmiany języka angielskiego; zob. Macafee, 1996, s. 151; Fenton, 2000, s. 10. 
- kalki semantyczne:

black frost 'ostry mróz'; black wind 'ostry wiatr'; black starvation 'wielki głód'; black fast 'ścisły post'; black North 'czarna Północ (protestancka część Ulsteru)'; black Protestant 'skrajny protestant';

widow-woman 'wdowa' (< irl. baintreach mná 'wdowa' < baintreach 'wdowa' + mná D. od bean 'kobieta'); half-twin 'bliźniak' (< irl. leathchúpla 'jedno z bliźniąt' < leath 'pół' + cúpla 'para');

- thumaczone zwroty:

the man of the house 'człowiek domu (gospodarz)' (< irl.fear an tigh); (a hundred) thousand(s) welcomes '(sto tysięcy / tysiąc powitań; gorące powitanie' (< irl. cead mile fáilte);

- 'czułe słówka' (ang. terms of endearment):

a chara 'przyjacielu' $(<$ irl. a chara $<a$ 'partykuła wołacza' + cara 'przyjaciel'); agra 'kochanie' (< irl. a ghrá < a 'partykuła wołacza' + grá 'miłość'); aneen 'dziewczynko; dziecko' ( $<$ irl. a inion $<$ a 'partykuła wołacza' + inion 'córka'); aroon 'skarbie' (< irl. a rún $<$ a 'partykuła wołacza' + rún 'skarb').

Zarówno wśród pospolitych zapożyczeń, jak i form hybrydalnych dość licznie występują deminutywa i im będą poświęcone dalsze części niniejszego artykułu³ .

\section{DEMINUTYWA W JEZYYKU IRLANDZKIM}

W języku staroirlandzkim istniało kilka różnych formantów deminutywnych, do najczęstszych należały -án (rodzaj męski lub niejaki) i -nat (rodzaj żeński) ${ }^{4}$ :

st.irl.fer (irl.fear) 'mężczyzna, mąż' > ferán;

st.irl. duine (irl. duine) 'człowiek, osoba' > duinán;

st.irl. lecc (irl. leac) 'kamień' > lecán;

st.irl. siur (irl. siúr) 'siostra'> siurnat;

st.irl. bó (irl. bó) 'krowa'> banat.

Rzadszym przyrostkiem było -én:

st.irl. duine (irl. duine) 'osoba'> duinén;

st.irl. caich (irl. caoch) 'ślepiec'> caichén.

3 Dla potrzeb niniejszego artykułu przyjmuje jedynie formalne kryterium identyfikowania deminutywów, czyli występowanie odpowiedniego formantu (w tym przypadku współczesnego irl. -ín oraz irl.-ang. -een), nie omawiam natomiast funkcji semantycznych deminutywów; zob. szczegółową dyskusję w: Jurafsky, 1996; uwagi na temat języka irlandzkiego w: Henry, 1957, s. 92; Bhaldraithe, 1990, s. 87; Doyle, 1992, s. 113-132 oraz obszerne opracowanie dotyczące języka angielskiego: Schneider, 2003.

4 Historyczny rozwój tych form przedstawia Rudolf Thurneysen [1980, s. 173-175]. 
Do pozostałych końcówek deminutywnych należały jeszcze -that, -ne, -ine oraz -éne. Dwa ostatnie formanty, razem z -én, przekształciły się we współczesnym języku irlandzkim w sufiks -ín. Jak zauważył Patrick Dinneen [1979, s. 594], ten formant pokrewny jest łacińskiemu -inus, -ina oraz walijskiemu -yn, -en. Natomiast we współczesnym języku irlandzkim można wyodrębnić trzy formanty deminutywne: -ín, -án, -óg, np..$^{5}$

-in: bád 'łódź' > báidín 'łódka';

-án: braon 'kropla'> braonán 'kropelka';

-óg: cnap 'sterta; bryła'> cnapóg 'bryłka'.

Jak zwracają uwagę Tomás de Bhaldraithe [1990, s. 86] oraz Aidan Doyle [1992, s. 126-127], dziś jedynie sufiks -ín jest produktywny, o czym świadczą deminutywa drugiego stopnia, gdzie pierwszym sufiksem jest -án lub -óg, np.:

cnoc 'wzgórze'> cnocán > cnocáinín 'wzgórek';

dronn 'garb; wypukłość' > dronnóg > dronnóigín 'małe wzniesienie'.

O żywotności tego sufiksu w języku irlandzkim świadczy zdolność tworzenia deminutywów ze stosunkowo nowymi zapożyczeniami angielskimi ${ }^{6}$, A. Doyle [1992, s. 125] podaje następujące formy:

puibin < irl. pub < ang. pub 'pub';

bruisin 'szczoteczka' < irl. bruis < ang. brush 'szczotka';

mótairín < irl. mótar < ang. motor 'motor'.

Innego dowodu na produktywność formantu dostarczają słowa, w których podstawą nie jest rzeczownik, ale np. spójnik, jak w przypadku aguisin 'dodatek; aneks' < agus 'i, oraz'. Richard Wall [2001, s. 44] podaje także formę zanglicyzowaną: agusheen 'mały dodatek; przesada; ostatnie słowo w sprzeczce'7.

Liczni autorzy [np. Henry, 1957, s. 92, Bhaldraithe, 1990, s. 91] zwracaja uwagę, na to, że w języku mówionym sufiks -ín (realizowany w irl.-ang. jako -een) może być dodawany do większości irlandzkich i angielskich rzeczowników konkretnych i nazw własnych, zwłaszcza imion (zob. poniżej).

Za: Doyle, 1992, s. 115.

6 T. de Bhaldraithe [1990, s. 89] podaje przykłady wczesnych, jeszcze szesnastowiecznych, zapożyczeń angielskich w irlandzkim, w których pojawił się omawiany sufiks, np. beiltín < ang. belt 'pasek'; caipín < ang. cap 'czapka'; fidilin < ang. fiddle 'skrzypce'; pigín < ang. pig 'świnia'. Warto zauważyć w tym miejscu, że w żadnym z tych przypadków nie były to zapożyczenia wypełniające lukę leksykalną.

7 O jeszcze innych formach przyjmujących formant -in, m.in. czasownikowych, wspomina T. de Bhaldraithe [1990, s. 88-89]. 


\section{DEMINUTYWA W IRLANDZKIEJ ODMIANIE JEZZYKA ANGIELSKIEGO}

Wśród deminutywów występujących w irlandzkiej odmianie języka angielskiego można wyróżnić zapożyczenia z irlandzkim przyrostkiem -ín, z przyrostkiem -án, z przyrostkiem -óg, formy hybrydalne (z formantem -een), wtórne zapożyczenia oraz dublety. Poniższe przykłady pochodzą przede wszystkim ze słowników i leksykonów odnotowanych w bibliografii:

- zapożyczenia z przyrostkiem -ín:

bawneen, baneen 'luźna flanelowa marynarka' (< báinín 'flanela; biała marynarka'< bán 'biały' + in);

boreen, bohereen 'ścieżka, dróżka' (< bóthairín 'ścieżka' < bóthar 'droga' + in); brogueen 'bucik' (< bróigín 'bucik' < bróg 'but' + in $)$;

carrageen 'jadalne wodorosty naskalne' $(<$ carraigin < carraig 'skała' + in $)$; colleen, cailin 'dziewczę' (< cailín 'dziewczę' < caile 'dziewczyna' + in $)$; gorteen 'poletko' (< goirtín 'poletko'< gort 'pole' + in $)$;

shebeen 'melina' $(<$ sibin 'nielegalnie pędzona whiskey' < séibe 'dzban; kubek'+in).

- zapożyczenia z przyrostkiem -án:

bracken 'pled' (< breacán 'pled, koc' < breac 'nakrapiany' + án);

casan 'ścieżka' (< cosán 'ścieżka' < cos 'stopa' + án);

leprechaun 'krasnal' (< st.irl. lú 'mały' + corpán 'małe ciało'< corp 'ciało' + án); lochan, loughan 'jeziorko, staw' (< loch 'jezioro' + án).

- zapożyczenia z przyrostkiem -óg:

shamrock 'koniczynka' (< seamróg < seamar 'koniczyna' +óg);

sheeogue, sheeoge 'duszek; odmieniec' (< sióg < si' 'duszek; wróżka' + óg).

- hybrydy (irl-.ang. -een $<$ irl. -in):

beddeen ( $<$ bed 'łóżko'); biteen ( $<$ bite 'kęs'); boyeen ( $<$ boy 'chłopiec'); breezheen ( $<$ breeze 'wiaterek'); dropeen ( $<$ drop 'kropla'); girleen $(<$ girl 'dziewczyna'); glasheen, glawsheen ( $<$ glass 'szklanka'); goosheen $(<$ goose 'gęs'); maneen (< man 'człowiek'); shoppeen (< shop 'sklep'); squireen $(<$ squire 'dziedzic'); whileen $(<$ while 'chwila').

- imiona:

Billeen, Cathleen, Doreen, Mikeen, Noreen, Pegeen, Rosaleen, Tomeen.

W przypadku wtórnych zapożyczeń podstawę stanowi element angielski, który najpierw przeszedł do języka irlandzkiego, następnie nowa forma irlandzka uległa deminutywizacji (często o zmienionej semantyce) i w takiej postaci przeszła do irlandzkiej odmiany języka angielskiego: 
pairceen 'poletko' (< irl. páircín < irl. páirc 'pole'< ang. park);

pinkeen 'płotka' ( $<$ irl. pincín < ang. pink 'różowy');

poteen, pottheen, posheen 'samogon' ( $<$ irl. poitín $<$ irl. pota $<$ ang. pot 'gar').

Ostatnim zagadnieniem, wspomnianym w niniejszym krótkim omówieniu deminutywów w irlandzkiej odmianie języka angielskiego, jest występowanie dubletów. To zjawisko dość rzadkie, ale niezmiernie ciekawe. W niektórych przypadkach w tej odmianie występują zarówno formy hybrydalne, jak i zapożyczenia dotyczące tych elementów leksykalnych z tego samego pola semantycznego, np.:

priesteen ( $<$ ang. priest 'ksiądz') $\sim$ sogarteen ( $<$ irl. sagart 'ksiądz');

girleen ( $<$ ang. girl 'dziewczyna') $\sim$ colleen ( $<$ irl. cailín $<$ caile 'dziewczyna');

pairceen 'poletko' ( $<$ ang. park) $\sim$ gorteen ( $<$ irl. goirtín $<$ gort 'uprawne pole').

Jak zauważył James Clark [1917, s. 28], pozornie synonimiczne pary różnią się konotacjami, dzięki czemu dają większą możliwość precyzyjnego dookreślenia, np. $\mathrm{z}$ dwóch podobnych wyrażeń: girleen i colleen, słowo colleen dotyczy przede wszystkim dziewczyny ze wsi. Dla ustalenia dokładnych różnic i podobieństw w występowaniu i odcieniach znaczeniowych powyższych dubletów należałoby przeprowadzić dokładne badania materiałowe i ankietowe ${ }^{8}$.

\section{ZAKOŃCZENIE}

Formanty słowotwórcze nie należą do kategorii często podlegających zapożyczeniom. Obecność irlandzkich formantów deminutywnych w irlandzkiej odmianie języka angielskiego świadczy o wielowiekowych kontaktach językowych, a jednocześnie o zapełnieniu pewnej luki słowotwórczej we współczesnym języku angielskim. Nacechowanie morfologiczne pozwala na rozszerzenie barwy znaczeniowej podstawowych jednostek, w tej funkcji deminutywa i irlandzkiej odmianie języka angielskiego są często wykorzystywane w literaturze.

BIBLIOGRAFIA

\section{Konsultowane słowniki}

DinNeEn Patrick, 1927 [1979], Foclóir Gaedhilge agus Béarla: An Irish-English Dictionary, Dublin.

Dolan Terence, 2004, A Dictionary of Hiberno-English. The Irish Use of English, second edition, Dublin.

8 Warto zauważyć, że zarówno sogarteen, jak i priesteen mają zabarwienie pejoratywne; zob. Share, 2005, s. 253, 303; Dolan, 2004, s. 183; Wall, 2001, s. 279. 
Fenton James, 2000, The Hamely Tongue. A Personal Record of Ulster-Scots in County Antrim, new revised edition, Belfast.

Macafee Caroline, 1996, A Concise Ulster Dictionary, Oxford.

Moylan Séamus, 1996, The Language of Kilkenny. Lexicon, Semantics, Structures, Dublin.

Ó DóNAILl Niall, 1977, Foclóir Gaeilge-Béarla, Dublin.

Ó Muirithe Diarmaid, 1996, A Dictionary of Anglo-Irish. Words and Phrases from Gaelic in the English of Ireland, Dublin.

Share Bernard, 2005, Slanguage. A Dictionary of Irish Slang and Colloquial English in Ireland, new and expanded edition, Dublin.

WaLL Richard, 2001, An Irish Literary Dictionary and Glossary, Gerrards Cross.

\section{Opracowania}

BhaldRaithe Tomás de, 1990, Notes on the diminutive suffix -in in Modern Irish, w: Celtic Language, Celtic Culture: A Festschrift for Eric P. Hamp, pod red. A.T.E. Matonis, D.F. Melia, Van Nuys, CA., s. 85-95.

Buiss Alan, 1972, Languages in contact: Some problems of Hiberno-English, „Proceedings of the Royal Irish Academy”, Vol. 72, Sec. C, Nr 3, s. 63-82. Buiss Alan, 1979, Spoken English in Ireland 1600-1740, Dublin.

Clark James, 1917, The Vocabulary of Anglo-Irish, St. Gallen.

Corrigan Karen, 2010, Dialects of English. Irish English. Volume 1 - Northern Ireland, Edinburgh.

Doyle Aidan, 1992, Noun Derivation in Modern Irish. Selected Categories, Rules and Suffixes, Lublin.

Henry Patrick L., 1957, An Anglo-Irish Dialect of North Roscommon, Dublin. HickEY Raymond, 2007, Irish English. History and Present-day Forms, Cambridge. HogAN Jeremiah J., 1927, The English Language in Ireland, Dublin.

JoYCE Patrick Weston, 1910 [1979], English as We Speak it in Ireland, Dublin. JURAFSKY Daniel, 1996, Universal tendencies in the semantics of the diminutive, „Language”, 72, s. 533-578.

SchNeIDER Klaus P., 2003, Diminutives in English, Tübingen.

Stalmaszczyk Piotr, 2007, Deminutywa w irlandzkiej odmianie języka angielskiego, „Słowotwórstwo i tekst. Prace Slawistyczne”, 124, s. 231-236.

Stalmaszczyk Piotr, 2009, Language Contact and Word-formation: Diminutive Forms in Irish English, „Issues in Celtic Linguistics. Lublin Studies in Celtic Languages", 5, s. 205-220.

Thurneysen Rudolf, 1946 [1980], A Grammar of Old Irish, Dublin. 